\title{
Student perceptions of preceptorship learning outcomes in BSN programs
}

\author{
Leslee H. Shepard ${ }^{1-3}$ \\ 1. Winston Salem State University, Winston-Salem, USA. 2. Indiana Wesleyan University, Marion, USA. 3. Chamberlain \\ College of Nursing, Addison, USA.
}

Correspondence: Leslee H. Shepard. Address: 78 Luzelle Drive, Winston Salem NC, USA. Email: shepardl@wssu.edu

Received: December 25, 2013

Accepted: February 10, 2014

Online Published: March 11, 2014

DOI : $10.5430 /$ jnep.v4n5p73

URL: http://dx.doi.org/10.5430/jnep.v4n5p73

\begin{abstract}
Preceptorships are models of training in which a nurse, referred to as a preceptor, is assigned to one nursing student, for the purpose of facilitating learning in the clinical setting. The purpose of this study was to evaluate nursing students' perception of the effectiveness of a newly implemented preceptorship. The mixed-method research design used a sequential explanatory strategy. Data collection methods included course evaluative surveys, interviews, and student academic records. The results of this study showed that students believed that preceptorships enhance learning. This study contributes to positive social change by providing guidance for nursing curriculum development, which could result in graduates being better prepared to serve the community through safe and competent nursing practice.
\end{abstract}

\section{Key words}

Preceptorship, Internship, Preceptor, Clinical education, Pre-service learning, Student nurse, Transition to practice, Student perceptions, Focused-client care

\section{I ntroduction}

Pre-service training programs in nursing schools are essential for helping student nurses apply theory to practice. Preceptorships are models of training in which an experienced licensed nurse is paired with a nursing student for the purpose of facilitating learning in the clinical setting. However, there is inadequate documentation on the understanding of these programs in the education learning outcome for $\theta$ f nursing students ${ }^{[1,2]}$. The purpose of this mixed methods study was to evaluate student perceptions of learning outcomes of a newly implemented focused client care preceptorship. The preceptorship provided senior nursing students the opportunity to practice in the clinical setting in a one-on-one relationship with a licensed registered nurse who functioned as the student's preceptor. The study used a mixed method design. The rationale for selecting this design was to gain greater insight into the effectiveness of the new preceptorship program by combining quantitative and qualitative data ${ }^{[3]}$.

\subsection{Background}

Transferring knowledge learned in the classroom such as effective critical thinking skills to the clinical setting can be difficult for some nursing students ${ }^{[3-5]}$. In addition, nursing faculty sometimes find it difficult to incorporate teaching strategies that will effectively facilitate transfer of theoretical knowledge to practice. 
The future of quality healthcare is heavily dependent on the preparation of new nurses. There are relevant articles within the literature related to the lack of clinical competence of new graduate nurses ${ }^{[3,6-8]}$. However, little is documented on alleviating perhaps the most prevalent barrier, student learning in the clinical setting.

Schools of nursing as well as regulatory agencies such as state boards of nursing are focusing their attention on implementing best practices that facilitate student learning in the clinical settings. DeYoung ${ }^{[5]}$ reports that the impetus for preceptorship development was the result of different issues but primarily the need to facilitate student transition into clinical practice ${ }^{[3]}$.

Clinical teaching is an invaluable instructional tool used to help develop the nursing skills of nursing students. Despite relentless efforts of nursing faculty, new nurses continue to have difficulty making the transition from student to practicing nurse. Recognizing this problem is the gateway to begin efforts to alleviate the problem.

The implementation of a preceptor program may be a better option that allows for a more refined teaching and learning atmosphere. According to Billings and Halstead ${ }^{[4]}$, preceptors are considered the experts in their area of specialty. These nurses enjoy teaching and should be able to do so effectively. The role of the faculty member is to first select an appropriate clinical agency, select the desired type of unit within the agency, and then select a preceptor who has been appropriately trained for a preceptorship experience.

The literature review for this study examined similar studies related to clinical teaching and effectiveness. There is substantial evidence supporting the importance of effective teaching and learning in the clinical setting for nursing students. Holmes ${ }^{[9]}$, examined students' and teachers' perceptions of effective clinical teaching by comparing part-time faculty to full-time faculty. The study was conducted using a non-experimental descriptive comparative survey design. The research findings suggested that there were no statistical significance of learning outcomes when part-time faculty was compared to full-time faculty. However, pertinent themes did emerge related to faculty behavior and characteristics that influenced learning in both a positive and negative manner ${ }^{[3]}$. Holmes ${ }^{[9]}$ identified positive key characteristics of clinical teachers as someone who is an expert in the field and takes pleasure in being a teacher. According to Shepard ${ }^{[3]}$, Tanicala ${ }^{[10]}$ conducted an exploratory study using both descriptive and inferential methods for the purpose of determining whether the design of a clinical curriculum in a baccalaureate nursing program could predict student success rates on the national council of licensure examination for registered nurses (NCLEX-RN). The outcome of this study was inconclusive. There were no identifiable variables within the curriculum of clinical designs that significantly influenced student success rates on the NCLEX-RN. The recommendation was for future research to be conducted that combines a qualitative and quantitative method that might generate more understanding to the complexities of nursing education in the clinical setting.

Price ${ }^{[2]}$ conducted a qualitative study with the purpose of developing a theory about the use of a preceptor model of clinical teaching according to the perceptions of senior level baccalaureate nursing students. Price concluded that although factors that enhanced clinical learning in a preceptorship did emerge, the validity of the findings could be skewed due to the small sample size of eight participants. Therefore, Price recommended that the study be replicated using larger sample sizes then corroborate the findings with her study. She also suggested the need to study the preceptorship model of clinical teaching from the preceptors' perceptions in order to expand upon the current knowledge ${ }^{[3]}$.

Kim ${ }^{[11]}$ conducted a study with a descriptive correlational design to explore the perceptions of senior baccalaureate nursing students about their clinical preceptorship program experiences. The study addressed three research questions with one being particularly similar to this current proposed study. That research question refers specifically to senior nursing students perceptions of clinical competency after a preceptorship rotation ${ }^{[3]}$. This is directly related to the correlation of preceptorships on clinical competence as with the current study. The sample size of 108 included senior nursing students enrolled in the final clinical course of a baccalaureate nursing program located in California. The primary instrumentation 
used was a 52-item Likert-type scale questionnaire. After analysis the results showed that there was a positive correlation between clinical preceptorship programs and nursing competence skills as perceived by senior nursing students.

\subsection{Theoretical framework}

A review of the literature reveals different models of clinical teaching, most seem to be grounded in the theories of adult learning ${ }^{[12-15]}$. Nursing programs, made up of an extremely diverse group of men, women, all ethnicities and backgrounds, have an average age of $27^{[1,4]}$. The learning styles of the collective group are equally diverse. Providing effective learning experiences for all students is challenging at best. Perhaps the only consistency within a group of nursing students is that they are all adults. Theorists have constructed models of learning that specifically address the needs of the adult learner.

Malcolm Knowles' ${ }^{[16]}$ andragogical model of learning proposed that adult learners are self-directing learners. Within this model, the assumption is made that adults take on some of the responsibility to learn when they have a specific need to know something in order to be more effective in some area of their life ${ }^{[3]}$. Nursing students fit this characteristic because they are classified as adult learners who have chosen to be in school. According to the andragogical model, this personal choice motivates the student to learn. Also, consistent with Knowles' theory of the adult learner, nursing students bring to the table a lifetime of experiences with teaching and learning. Knowles ${ }^{[17]}$ contended that adult learners prefer selfdirection with learning primarily due to their busy lifestyles; nurse educator's understanding of this preference will help to guide clinical teaching strategies most conducive to learning ${ }^{[3]}$.

Patricia Benner's novice-to-expert model ${ }^{[18]}$ will be the second theoretical framework used for this study. The noviceto-expert model was based on the premise that skill acquisition of students and practicing nurses is built on levels of proficiency and can be evaluated by a change in skill performance of the learner. The levels identified in Benner's noviceto-expert model are novice, advanced beginner, competent, proficient, and expert. According to Benner's typology, the levels most representative of nursing students are the novice and the advanced beginner ${ }^{[3]}$.

\section{Methods}

\subsection{Setting and sample}

The population for the study was identified as 47 senior nursing students enrolled in a traditional pre-licensure baccalaureate nursing program in the Triad Region of North Carolina. All 47 were enrolled in the capstone course during the spring semester of 2009. The exclusion criteria was any student who had not completed the 120-hour focused client care preceptorship program at the time of the data collection as evidenced by performance evaluations completed by the preceptor and the nurse faculty.17 were excluded.

Records from all 47 students were collected and 30 included all data needed to be analyzed for the study. The audiotape of a semi-structured focus group interview, conducted with end of course evaluations, was also used. Written permission for data use and a letter of cooperation from the Dean of Nursing were obtained prior to the study.

Consent forms were obtained since the data had to be used in the study. Those who volunteered completed the Preceptorship Effectiveness Questionnaire (PEQ-SP) electronically and then completed a focused group interview in a private conference room. The interview was audio-taped. The data were collected during the last week of university classes in the spring of 2009.

Because the purpose of this study was for the completion of a doctoral dissertation, approval for the study was obtained from both the author's school as well as the school the study was conducted. Institutional Review Board (IRB) \# 06-03-09-0340698. A signed letter of cooperation and data use agreement forms were obtained from the Dean of Nursing 
at the university in which data was collected. These written letters gave permission to collect, analyze, and use specific documents needed to conduct this study.

\subsection{I nstruments}

This study was conducted by means of analysis of preexisting course documents. The procedure used to collect data for this study was guided by sequential triangulation, a mixed methods strategy. The purpose for using this method was to gain greater insight using multiple sources to validate the findings. Data collected was retrieved from both quantitative and qualitative instruments that were previously collected during the normal course of the spring 2009 academic semester.

\section{Qualitative instrument}

An interview guide was used for the focused group interview. The interview protocol consisted of five open ended questions that were used to guide the discussion. The questions were: 1) To what extent do you believe professionalism was impacted as a result of the experience? 2) In what ways do you believe the preceptorship experience facilitated your confidence? 3) Describe examples of how preceptorship help develop your critical thinking skills? 4) In what ways did you use communication skills with patients, family, and interdisciplinary teams? And, 5) Do you believe preceptorship helped to develop nursing skills such as IV therapy, dressing changes and other skills? Yes or no and why?

\section{Quantitative instrument}

The instruments used to collect quantitative data included copies of the student's performance evaluations completed at the end of the preceptorship rotation, and electronic copies of the participants' responses to a titled Preceptorship Effectiveness Questionnaire (PEQ-SP) completed with university end-of-course evaluations.

The PEQ-SP is a 32-item five-point ordinal Likert-type scale questionnaire. Questions are based on five dimensions of clinical competence: professionalism, confidence level, critical thinking, communication skill, and clinical skill development. Professionalism reflected students' ability to work with difficult people in the work setting, work ethics, accountability for time and attendance, and the ability to be self-directed learners when faced with issues.

Confidence level addressed students' perceptions of how they perceived an improvement in their professionalism, communication, both verbal and written, clinical nursing skills, overall professionalism, and critical thinking.

Critical thinking covered students' ability to think critically through complex situations.

Communication skills involved students' perceptions of their ability to be effective communicators in both written and verbal forms when communicating with primary care providers and other professionals. These items also addressed shift change reporting skills and the ability to effectively delegate to nursing assistants.

Skill development involved skills that students were allowed to complete within their scope of practice as a student nurse. Head to toe assessments, medication administration, and intravenous line management were the primary clinical nursing skills addressed.

The PEQ-SP was designed by course faculty. Reliability and construct validity of the PEQ-SP were determined prior to use by examining intercoder reliability. Four additional faculty members, including one full tenured professor, and assistant professors independently reviewed the instrument to determine how well the items measured each intended theme, content, and face validity. The original survey was revised based on that feedback.

To pilot the instrument the survey was passed out to 24 nursing students at the senior level with characteristics similar to those of the targeted population. Each student was asked to voluntarily complete the survey and provide feedback on the clarity of each of the questions. Nine (38\%) surveys were returned. Although no items were deleted, the survey was modified again based on the feedback provided. 
The survey, designed to be completed in 10 minutes or less, was administered by the course coordinator during a regularly scheduled class period with all other end of course evaluations at the end of each semester. A continuation of reliability testing was done on the actual survey results using cronbach alpha to determine internal consistency reliability. Results that are .70 or higher are considered to be in the acceptable range ${ }^{[19]}$. As such, the result of the PEQ-SP has acceptable reliability with a Cronbach's alpha reaching $.890^{[3]}$. While all items on the instrument were designed using a 5-point Likert type scale, there were three different category scales. Items 1- 26 used the following category scale: 4-Strongly Agree, 3-Agree, 2-Disagree, 1-Strongly Disagree, and 0-Not able to judge. The category scale used for items 27-31 was; 4-Very helpful, 3-Helpful, 2-Somewhat helpful, 1-A little helpful, and 0-Not able to judge. The last item, number 32 used 4-Very Satisfied, 3-Satisfied, 2-Somewhat satisfied, 1-A little satisfied, and 0-Not at all satisfied.

Five themes related to clinical competence were used to generate all 32 items. The themes were: (a) professionalism, (b) confidence level, (c) critical thinking, (d) communication skills, and e) skill development. The themes were derived using the American Association of Colleges and Nursing (AACN) Essentials of Baccalaureate education for professional Nursing Practice ${ }^{[20]}$ as a guide.

Student-records were collected from a password secured electronic database available to faculty. The records were coded numerically to match participants and then de-identified to maintain confidentiality. Students' final preceptorship performance evaluations were obtained from schools administrative offices individual student files. The evaluations were also de-identified using the same coding process used so that student scores were for the same students' as the evaluations. The student performance evaluation tool was designed by the faculty of the nursing program. Both face and content validity were established by faculty prior to use; however, no reliability of the evaluation tool had been established.

Confidentiality of the interviews was maintained by storing the hand held recording device with the electronic transcriptions in a locked file cabinet. Actual student names were not used in the final results; rather, code names such as Student 1 and Student 2 were assigned. The focused group interview and interviews were using standard qualitative procedures. The first step was to transcribe the interview in its entirety. The transcriptions were then read and reread to identify themes, to code, and make sense of the data. No software program was used to assist with this process. Traditional handwritten notes with multicolored highlighters were used to organize, structure, and identify themes generated throughout the data.

All 47 students' files had evidenced of completion of the preceptorship program, only 30 (63.8\%) of the students' files contained student performance evaluations completed by the preceptors who worked with them one-on-one and could have provided more in depth insight on learning outcomes. All 47 students had performance evaluations in their files with anecdotal notes from the course faculty. Nine students participated in the audio recorded group interview.

To summarize, of the 47 students in the population, the final number that met all inclusion criteria was 30 . Nine of those participated in the focused group interview.

\section{Sample characteristics}

The great majority of the samples were female nursing students (93\%) while 7\% were males. The average age of the sample was 31 years. Fewer than $35 \%$ of the class was in the traditional college graduate age range of 22-24.

The program reviewed for this study was at a historically black university and $47 \%$ of the sample indicated that their racial background was African American, followed by 40\% White, and the remaining 13\% selected other.

Students were assigned to four specialty areas in two local acute-care hospital settings for the preceptorship experience. $43.3 \%$ of students were assigned to medical surgical units, $10 \%$ in the cardiac or transitional intensive care unit (TICU), $36.7 \%$ in the critical care units, and 10\%in the emergency department (ED) (see Table 1). 
Table 1. Respondent’s Preceptorship Specialty Area

\begin{tabular}{llll}
\hline Location & Frequency & Percent & Cumulative Percent \\
\hline Medical Surgical & 13 & 43.3 & 43.3 \\
Emergency Dept & 3 & 10.0 & 53.3 \\
Cardiac or Transitional ICU & 3 & 10.0 & 63.3 \\
Critical Care & 11 & 36.7 & 100.0 \\
Total & 30 & 100.0 & \\
\hline
\end{tabular}

\section{Results}

\subsection{Research question one}

What are student perceptions of preceptorships on enhancing clinical competence? This question was addressed using both quantitative and qualitative data. Quantitative data came from the 32-item PEQ-SP.

\section{Quantitative}

Responses from each of the 30 surveys were entered into the analysis software database. Pearson's correlation tests were ran on each of the set of items within each theme. Several items showed a significant correlation at the 0.05 level as well as the 0.01 level. Only those items that reached a significant level of $p<.05$ were considered relevant for this study.

The data on professionalism indicated that the items 29) Overall professionalism, 5) I researched additional information on unfamiliar topics I encountered during the work shift, and 8) I referred to the facilities policy and procedure manual at least weekly were worthy of further analysis. The data on communication indicated items 9) In addition to electronic documentation, I documented directly in the progress notes each work day, 18) I had ample opportunities to communicate patient findings to the primary care providers, 20) My professional communication skills have improved as a result of the preceptorship experience, and 30) Professional communication skill, produced a $p<.05$ significance level and were looked at more closely.

The last set of items was on skill development. Item 3) I had 3 or more opportunities to attempt to start peripheral intravenous (IV) lines and 15) I performed head to toe assessments each work day of my preceptorship reached $p<.05$ significance level.

Multiple one way analysis of variance (ANOVA) on each of the dependent variables which corresponded to the five themes of the PEQ-SP instrument was conducted. The purpose for conducting this analysis was to determine if there was a mean difference in student perceptions between the four practice areas of students' preceptorship rotations. Those specialty areas were medical surgical, intensive care units, cardiac care units or transitional intensive care, and the emergency department. There were minimal differences with student satisfaction in the different settings used in the hospital. Table 2 is the ANOVA report. According to Gravetter \& Wallnau ${ }^{[21]}$, when using ANOVA to determine whether significant differences between samples are present, the between treatments referred to as the numerator should be a larger number than the within treatments referred to as the denominator, in addition the F-ratio would be near $1.00{ }^{[21]}$.

There were no significant differences of students' perceptions about preceptorship location relevant to the 6 items. Results for these items were: confidence level $F(3,26)=.404, p<.751$; clinical skill development $F(3,26)=.079, p<.971$; professionalism $F(3,26)=.366, p<.778$; communication skills $F(3,26)=.079, p<.971$; nor critical thinking $F(3,26)$ $=.342, p<.795$. The last ANOVA reports showed no significant difference of student's perceptions about preceptorship location and their overall satisfaction with the program, $F(3,26)=.043, p<.988$. The output displayed did not show any significant difference for the six themes among the four specialty locations; therefore, it was concluded that students' perceptions of clinical competence was not affected by the location of their preceptorship rotation. 
Figure 1 compares students' assigned preceptorship location within the hospital setting and item 32 which asked about their overall satisfaction. The bar graph showed minimal differences with student satisfaction across different settings.

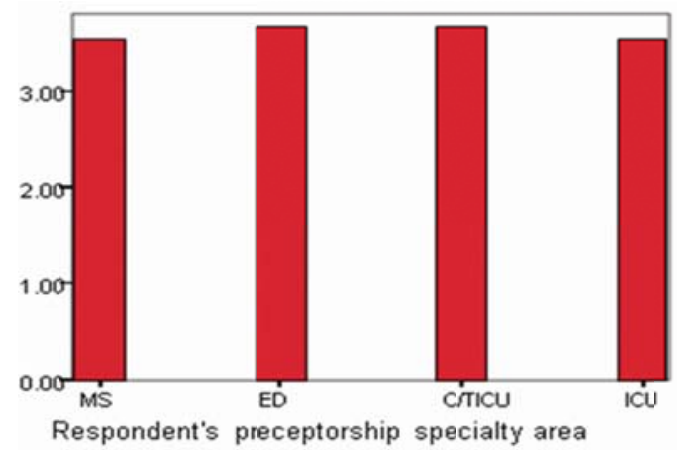

Figure 1. Comparison of student's assignment area with their overall satisfaction MS= Medical Surgical, ED=Emergency Department, C/TICU=Cardiac or Transitional Intensive Care Unit, ICU=Intensive Care Unit.

Table 2. Analysis of Variance by Specialty Location and Theme

\begin{tabular}{|c|c|c|c|c|c|c|}
\hline & & Sum of Squares & df & Mean Square & $F$ & Sig. \\
\hline \multirow{3}{*}{$\begin{array}{l}\text { Item } 27 \\
\text { Confidence }\end{array}$} & $\begin{array}{l}\text { Between } \\
\text { Groups }\end{array}$ & .511 & 3 & .170 & \multirow{3}{*}{.404} & \multirow{3}{*}{.751} \\
\hline & $\begin{array}{l}\text { Within } \\
\text { Groups }\end{array}$ & 10.956 & 26 & .421 & & \\
\hline & Total & 11.467 & 29 & & & \\
\hline \multirow{3}{*}{$\begin{array}{l}\text { Item } 28 \\
\text { Clinical Skills }\end{array}$} & $\begin{array}{l}\text { Between } \\
\text { Groups }\end{array}$ & .229 & 3 & .076 & \multirow{3}{*}{.079} & \multirow{3}{*}{.971} \\
\hline & $\begin{array}{l}\text { Within } \\
\text { Groups }\end{array}$ & 25.138 & 26 & .967 & & \\
\hline & Total & 25.367 & 29 & & & \\
\hline \multirow{3}{*}{$\begin{array}{l}\text { Item } 29 \\
\text { Professionalism }\end{array}$} & $\begin{array}{l}\text { Between } \\
\text { Groups }\end{array}$ & .454 & 3 & .151 & \multirow{3}{*}{.366} & \multirow{3}{*}{.778} \\
\hline & $\begin{array}{l}\text { Within } \\
\text { Groups }\end{array}$ & 10.746 & 26 & .413 & & \\
\hline & Total & 11.200 & 29 & & & \\
\hline \multirow{3}{*}{$\begin{array}{l}\text { Item } 30 \\
\text { Communication }\end{array}$} & $\begin{array}{l}\text { Between } \\
\text { Groups }\end{array}$ & .175 & 3 & .058 & \multirow{3}{*}{.079} & \multirow{3}{*}{.971} \\
\hline & $\begin{array}{l}\text { Within } \\
\text { Groups }\end{array}$ & 19.291 & 26 & .742 & & \\
\hline & Total & 19.467 & 29 & & & \\
\hline \multirow{3}{*}{$\begin{array}{l}\text { Item } 31 \\
\text { Critical Thinking }\end{array}$} & $\begin{array}{l}\text { Between } \\
\text { Groups }\end{array}$ & .511 & 3 & .170 & \multirow{3}{*}{.342} & \multirow{3}{*}{.795} \\
\hline & $\begin{array}{l}\text { Within } \\
\text { Groups }\end{array}$ & 12.956 & 26 & .498 & & \\
\hline & Total & 13.467 & 29 & & & \\
\hline \multirow{3}{*}{$\begin{array}{l}\text { Item } 32 \\
\text { Satisfaction }\end{array}$} & $\begin{array}{l}\text { Between } \\
\text { Groups }\end{array}$ & .075 & 3 & .025 & \multirow{3}{*}{.043} & \multirow{3}{*}{.988} \\
\hline & $\begin{array}{l}\text { Within } \\
\text { Groups }\end{array}$ & 15.291 & 26 & .588 & & \\
\hline & Total & 15.367 & 29 & & & \\
\hline
\end{tabular}

Students perceived professionalism to be the area of clinical competence most enhanced by their preceptorship. The total mean score for item 29 which measured overall professionalism was 3.60 with a standard deviation of .621. Confidence 
level in nursing had a total mean score of 3.53 and standard deviation of .628. Critical thinking was close at 3.53 and a standard deviation of .681. Item 30 representing communication was the fourth most enhanced area of clinical competence with a total mean score of 3.46 and standard deviation of .819. Surprisingly, the component of clinical competence that ranked lowest was clinical skill development with a total mean score of 3.43 and $.935^{[3]}$.

Students' perceived overall professionalism was the area most enhanced by completing a preceptorship experience with a composite of 4.20. The area rated as least enhanced by students was communication skills with a 3.10 composite score. Figure 2 represents the score assigned to each of the five themes.

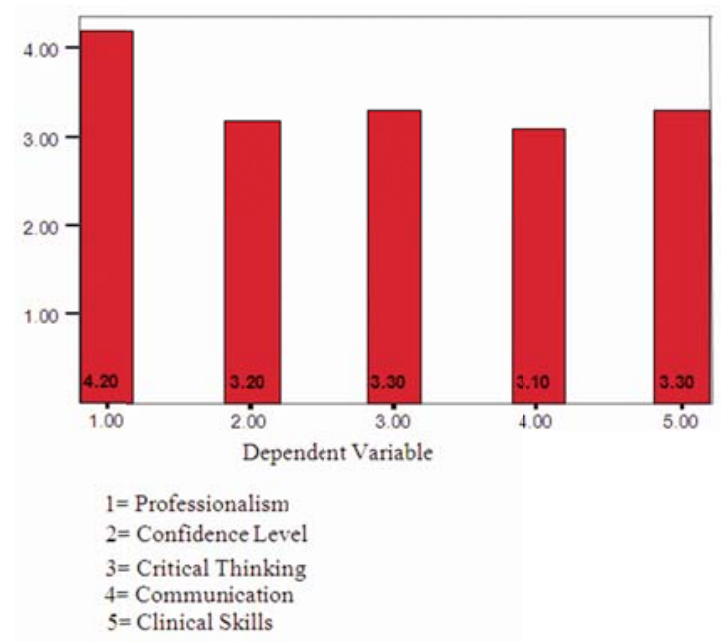

Figure 2. Mean score of each dependent variable or theme of clinical competence.

\section{Qualitative data}

Five of the nine students who participated in the interview reported the medical surgical setting as their assigned unit, whereas, three reported cardiac units, one for the intensive care unit, none of the nine reported working in the emergency department.

Each student provided a general description of a typical shift in the clinical setting with their assigned preceptor. All students worked 12 hour shifts. Five reported being on the night shift from 7 p.m. to 7 a. m. rotations, 3 worked the day shift of 7 a.m. to 7 p.m. and one student did not mention her shift.

Students arrived 15 to 30 minutes prior to the start of the shift, as required by the assigned facility. All students participated in shift change report at the beginning of the shift. All were involved in planning care and had opportunities to perform head to toe assessments on their assigned patients each shift ${ }^{[3]}$.

Major differences emerged as students described the types of nursing skills they were faced with each day. The primary reasons for the differences were the type of unit, the acuity level and diagnoses of the unit's patient population. Hospitalized patients admitted on a general medical surgical unit typically have a lower acuity level and require less intense care than those admitted to an intensive care unit. This became evident as the students described the activities they were exposed to during their rotations ${ }^{[3]}$.

Student 2 said, "I was able to do an NG tube; that was the first time I ever did it and I was successful!" The excitement of her voice seemed to trigger other participants to interject their experiences. Student 3 immediately followed with "I started an NG tube and got to attempt and start different IVs." Student 5 said "I got to do things that I have never done! That was awesome!” 
Student 4 who was assigned to an oncology unit, reported that due to the longevity of the patients and the fact that most had long-term central venous access devices, she "did not get to do a lot of hands on skills". Student 7 reported that although she was not able to perform a lot of skills, she did have a few opportunities "I was able to do EKGs, start IVs". She went on to report that her experiences, while not heavily weighted in direct hands-on skills, were just as beneficial because of being exposed to many different conditions. "I was able to see a couple of different amputations below-the-knee and abovethe-knee amputations. There were a lot of heart transplant rejection patients on peritoneal dialysis so I got a wide variety of a lot of patients." Student 9 seemed to best summarize the major goal of a preceptorship program when she stated "The whole experience helped me to take what I learned in the classroom and apply it to clinical setting."

\section{Professionalism}

When asked how professionalism was affected by the preceptorship, Student 1 said: I think it was because you got to see people in more of their core element rather than just being there in a group setting. With students and with a clinical instructor you were actually "the nurse" at that time, so you got to see well, for the most part for me was positive because on the night shift it's a real team approach in terms of everyone knowing who they are working with and everyone knowing their role but also wanting to fill in to help. You know just kind of make the night and shift go by well. I worked nights and weekend shifts and so those were typically the same people who worked that same schedule. So it was good in seeing that they all pulled together and they really depended on each other but they were also very reliant on each other in terms of getting things done. For the most part my preceptors were very professional and I knew that they wanted to model that kind of behavior because they knew I was there with them and they would point things out to me you know in terms of don't do that and you know this is always what you should always be careful about doing. You know if it came down to just making sure you verified meds very accurately to you know maybe stopping something properly. And they always pointed out to me you know even if you don't see other people doing it (med verification) you need to make sure that you are always doing it the way you need to do it.

\section{Confidence level}

In response to a question on whether the preceptorship experience facilitated their confidence level as a nurse, Student 7 said: My preceptor, after she realized what I could do, she kind of just let me go and do it. I did the assessments I was passing the meds and I would verify with her well if I wasn't comfortable doing something I would go and get her and she would come and stand by me and instruct me on how to do it. Student 2 said: Yeah, I feel the same way like my preceptor allowed me to give my meds, if I needed to change my IVs she would let me do that. She was also very professional on how to deal with things like she would not talk about something when the patient was in there but would come out and talk outside. And if I need help, like she said, I would always call my preceptor and she would explain what I needed.

\section{Critical thinking}

When asked how the preceptorships helped develop critical thinking skills, one student described how she and her preceptor noticed a difference from what was reported as the patient's normal level of consciousness and what was assessed. It was determined that the patient had had a stroke during shift change. The student reported that the experience was beneficial to her critical thinking development.

As the interview proceeded, students discussed issues with communication as they described patient issues that required notification of the physician or other primary healthcare provider. This discussion led into the interview guided question about communication.

\section{Communication skills}

When asked how preceptorship enhanced communication skills, one student reported that she contacted a respiratory therapist and nurse practitioner. Student 6 gave examples of how the preceptorship enhanced her 
communication skills, I feel like I got more respect to delegate because that was one of our duties of being a nurse to delegate instructions to CNAs [certified nursing assistants] and sometimes being that there is a large group of us [clinical group], I don't know, they[staff] get offended or intimidated by that but I feel like since it was just one-on-one[preceptor to student] they [CNA] had more respect and they were more open-minded and really respected that fact that this is a nurse in training right now and one of her responsibilities is delegating a job to do. That [delegation through communication] just helped me out in regards to communication when compared to my personal prior experiences [in the clinical setting].

This response led to an unanticipated perception of being treated differently in their role as student in a preceptorship experience than in the traditional rotation with a group of fellow students and clinical instructor. The entire group was asked if this was a mutual perception and the response was a unanimous yes ${ }^{[3]}$.

\section{Clinical skills}

In response to the final question on whether the preceptorship helped to develop nursing skills such as IV therapy, dressing changes and other skills, Student 7 said, yes and no because on my unit a GI unit so you get specific things as opposed to someone who went to ICU or somebody who went to the ED or who went to wherever they had a chance to constantly get all these different skills, my patients were just assessing and giving meds you know and students overwhelmingly believed the preceptorship experience was beneficial to their growth and development as nursing students.

Table 3. Summary of Qualitative Data

\begin{tabular}{|c|c|c|}
\hline Theme & Favorable Responses & Unfavorable Responses \\
\hline Professionalism & $\begin{array}{l}\text { Multiple responses indicated that students believed that they grew } \\
\text { professionally. Also perceived other staff treated them with respect like a peer. }\end{array}$ & \\
\hline Confidence Level & $\begin{array}{l}\text { Overall belief is that extended time focusing on patient care in a natural setting } \\
\text { helped to build confidence. } \\
\text { "It wasn’t an intimidating experience as compared to clinicals with } \\
\text { instructors" [at their side] } \\
\text { "My preceptor, after she realized what I could do, she kind of just let me go } \\
\text { and do it" }\end{array}$ & \\
\hline Critical Thinking & $\begin{array}{l}\text { Students presented stories of experiences they had with changes in patient's } \\
\text { medical condition and their role during those situations. } \\
\text { "...I went back and looked through all her past medical history and found that } \\
\text { she had a past medical history of stroke. So we had to go call emergency, } \\
\text { notify the doctor..." }\end{array}$ & \\
\hline $\begin{array}{l}\text { Communication } \\
\text { Skills }\end{array}$ & $\begin{array}{l}\text { “... toward the end I just got more comfortable writing it [progress notes]...” } \\
\text { Students also reported the need to call primary care provider regarding patient } \\
\text { concerns. }\end{array}$ & $\begin{array}{l}\text { The experience did not seem to decrease } \\
\text { anxiety when communicating with } \\
\text { physicians. } \\
\text { "...I thought he was going to think I } \\
\text { sounded like an idiot because that was my } \\
\text { first time ever having to have that } \\
\text { contact..." }\end{array}$ \\
\hline Skill Development & $\begin{array}{l}\text { When the participants asked if they believed the experience helped their skill } \\
\text { development the response was a unanimous yes with excitement in the tone. } \\
\text { Students reported certain units provided multiple opportunities. } \\
\text { "I was very intimidated with starting IVs cause I hadn't had much experience } \\
\text { and the whole time I was there I mean every nurse would say [student] come } \\
\text { and start this IV”. }\end{array}$ & $\begin{array}{l}\text { "I didn't get a lot of the hands on } \\
\text { experiences that I thought I would have } \\
\text { probably gotten if I was in the ED or the } \\
\text { ICU or even the med/surg" }\end{array}$ \\
\hline $\begin{array}{l}\text { Overall } \\
\text { Satisfaction }\end{array}$ & $\begin{array}{l}\text { "I had very interesting cases and learned a lot during my time there." } \\
\text { "And my experience was very good. I got to do things that I have never done! } \\
\text { That was awesome." } \\
\text { "The whole experience helped me to take what I learned in the classroom and } \\
\text { apply it to clinical setting." }\end{array}$ & $\begin{array}{l}\text { "I am fascinated with the heart so I would } \\
\text { like to be on a cardiac unit but I wasn't } \\
\text { given the opportunity to do my } \\
\text { preceptorship on a cardiac floor". }\end{array}$ \\
\hline
\end{tabular}


Table 3 provides a summary of the qualitative data with specific quotes relevant to each theme. Although there were comments that were not favorable, the benefits reported by the students seem to far outweigh the negative aspects of the $\operatorname{program}^{[3]}$.

The evaluations were of participants' clinical performance during their preceptorship, both forms and anecdotal notes written by the faculty were retrieved for review.

The original student performance evaluation tool was coded as only Satisfactory or Unsatisfactory. In an effort to generate more in depth information a new scale was created to take into account anecdotal notes made by the supervising faculty assigned to students. The following scale was created prior to analysis. Satisfactory $=1$; Satisfactory with minimal difficulties $=2$, assigned to any record with one to three notated concerns about student performance that was not favorable; Satisfactory with moderate difficulties $=3$ and was coded if any student's records had more than three negative type notes from the supervising faculty, and Unsatisfactory $=4$.

\section{Discussion}

Participants of the study perceived their preceptorship experience to have been beneficial for professionalism, communication, and clinical skills. Students did not perceive the experience to improve critical thinking. The interview analysis suggested that students gained confidence in their clinical performance as a result of the preceptorship experience.

Results indicated that nursing students perceived the preceptorship to be an invaluable learning experience that enhanced their competence in the clinical setting. Data was collected from the nursing students by means of preexisting questionnaires, interviews, and written performance evaluation. Limitations were identified with the small sample size and that the study was confined to one group of students. The study was narrowed in scope by confining itself to only collecting data on those senior nursing students who completed the preceptorship program in the spring semester of 2009. Replication of this study is recommended to include a larger sample size and data collected over time.

The interpretations also suggests that these students perceived preceptorship programs to be a positive aspect of their learning regardless of practice location. Students believed their experience had a positive impact on their professional growth in the area of general professionalism, communication skills, and performance of clinical nursing skills. Students did not believe their critical thinking skills or confidence level significantly changed.

\section{Conclusion}

There is sufficient evidence in the literature that supports preceptorship programs for helping students move across the learning continuum from student to nurse ${ }^{[1,3-5,8,22]}$. On the contrary, a ProQuest search engine generated a limited number of studies conducted years apart specifically on student perceptions of their experiences ${ }^{[2]}$. This study examined the effectiveness of a preceptorship experience for senior nursing students in a baccalaureate program.

Findings from this study reinforce the notion that students perceive preceptorship experiences to be beneficial for enhancing clinical competence and suggested that overall professionalism was perceived by students as the greatest enhanced learning area ${ }^{[3]}$. This study contributes to the literature by further validating the limited reported outcomes of the preceptorship experiences on nursing student's learning outcomes.

\section{References}

[1] Billings, D. M., \& Halstead, J. A. Teaching in nursing, a guide for faculty (3rd ed.). St. Louis, MO: Elsevier Saunders, 2009. 
[2] Price, P. J. Final year baccalaureate nursing students’ perceptions of a preceptor model of clinical teaching. Unpublished doctoral dissertation, University of Toronto, ON, Canada, 2006.

[3] Shepard, L.H. Examining the effectiveness of a preceptorship on clinical competence for senior nursing students in a baccalaureate program (Doctoral dissertation), 2010. Available from: ProQuest. (UMI 3396353).

[4] Billings, D. M., \& Halstead, J. A. Teaching in nursing, a guide for faculty (2nd ed.). St. Louis, MO: Elsevier Saunders, 2005.

[5] DeYoung, S. Teaching strategies for nurse educators. Upper Saddle River, NJ: Prentice Hall, 2003.

[6] Bjorkstrom, M. E., Athlin, E. E., \& Johansson, I. S. Nurses' development of professional self-from being a nursing student in a baccalaureate program to an experienced nurse. Journal of Clinical Nursing. 2008; 17(10): 1380-1391. PMid:18266848 http://dx.doi.org/10.1111/j.1365-2702.2007.02014.x

[7] Merriman, C., \& Bradshaw, A. Nursing competence 10 years on: fit for practice and purpose yet? Journal of Clinical Nursing. 2008; 17(10): 1263-1269. PMid:18416778 http://dx.doi.org/10.1111/j.1365-2702.2007.02243.x

[8] Wieland, D. M., Altmiller, G. M., Dorr, M. T., \& Wolf, Z. R. Clinical transition of baccalaureate nursing students during preceptored, pregraduation practicums. Nursing Education Perspectives. 2007; 28(6): 315-321. PMid:18240737

[9] Holmes, S. P. Student and faculty perceptions of clinical teaching effectiveness of full-time and part-time baccalaureate degree clinical nursing faculty. Unpublished doctoral dissertation, Auburn University, 2006, AL.

[10] Tanicala, M. L. Design and implementation of nursing student clinical experiences and program effectiveness as measured by NCLEX-RN pass rates. Unpublished doctoral dissertation, Bowling Green State University, OH, 2006.

[11] Kim, K. H. Clinical competence among senior nursing students after their preceptorship experiences. Journal of Professional Nursing. 2007; 23(6): 369-375. PMid:18053963 http://dx.doi.org/10.1016/j.profnurs.2007.01.019

[12] Bender, D. G. Experiencing the effect of teaching and learning styles on skill mastery. Journal of Nursing Education. 2007; 46(3): 147-148. PMid:17396556

[13] Dauer, L. T. Facilitating effective radiation safety workshops: Adult learning theories. Operational Radiation Safety. 2003; 85(suppl 1): 49-55.

[14] Diefenbeck, C. A., Plowfield, L. A., \& Herrman, J. W. Clinical immersion: a residency model for nursing education. Nursing Education. 2006; 27(2): 72-79.

[15] Gallant, M., MacDonald, J., \& Smith-Higuchi, S. A remediation process for nursing students at risk for clinical failure. Nurse Educator. 2006; 31(5): 223-227. PMid:16980827 http://dx.doi.org/10.1097/00006223-200609000-00010

[16] Knowles, M. Andragogy in action (1st ed.). San Francisco: Jossey-Bass, 1984.

[17] Knowles, M. Self-directed learning: a guide for learners and teachers. Cambridge New York: The Adult Education Co, 1975.

[18] Benner, P. From novice to expert: excellence and power in clinical nursing. Menlo Park, CA: Addison-Wesley, 1984.

[19] Gokhale, A., Brauchle, P., \& Machina, K. Development and validation of a scale to measure attitudes toward science and technology. Journal of College Science Teaching. 2009; 38(5): 66-75.

[20] American Association of Colleges of Nursing (2008). The essentials of baccalaureate education for professional nursing practice. Available from: http://www.aacn.nche.edu/Education/pdf/BaccEssentials08.pdf

[21] Gravetter, F. J., \& Wallnau, L. B. Essentials of statistics for the behavioral sciences (5th ed.). Belmont, CA: Thomson Wadsworth, 2005.

[22] Hickey, M. T. Nursing graduates’ attitudes toward their clinical instructional experience and preparation for practice. Dissertations Abstracts International, 2005. 